\section{Effects of Soil Salinity on Citrus Rootstock 'US-942' Physiology and Anatomy}

\author{
Sawyer N. Adams, Walter O. Ac-Pangan, and Lorenzo Rossi ${ }^{1}$ \\ Department of Horticultural Sciences, University of Florida, Institute of \\ Food and Agricultural Sciences, Indian River Research and Education \\ Center, Fort Pierce, FL 34945
}

\section{Additional index words. apoplastic barriers, citrus, rootstock, salt stress}

\begin{abstract}
The accumulation of salt deposits in the soil is becoming a major problem in agriculture. The problem can affect citrus production, which is already seriously hindered in Florida by the disease known as Huanglongbing (HLB, or citrus greening). With the citrus industry declining, it is imperative to study all potential environmental stresses affecting the citrus cultivation and to conduct screening tests to evaluate which rootstocks perform best under these challenging new conditions. This study aims to determine how the 'US-942' rootstock reacts to salinity. Thirty-six 3-month-old 'US-942' citrus rootstock seedlings were grown in a greenhouse. After 15 d of acclimation, plants were assigned to one of six groups and treated for $30 \mathrm{~d}$ with solutions of $25 \%$ Hoagland solution amended with 0 (control), 30, 60, 90, 120, or $150 \mathrm{~mm} \mathrm{NaCl}$. Higher $\mathrm{NaCl}$ concentrations significantly hindered plant growth and negatively affected some physiological processes [i.e., stomatal conductance $\left(g_{\mathrm{S}}\right)$ ] and chlorophyll contents. Conversely, plants treated with mild concentrations $(30 \mathrm{~mm} \mathrm{NaCl})$ had higher plant biomass and exhibited higher photosynthetic efficiency. Free hand sections of fresh roots were taken at the end of the experiment, and the suberin lamellae development was examined under a fluorescence microscope. In conclusion, results reported that ' US-942' rootstock is tolerant to mild salt stress and confirmed the hypothesis that the formation of root apoplastic barriers and the increase in the root biomass could be two possible mechanisms that give the 'US-942' a mild $\mathrm{NaCl}$ stress tolerance.
\end{abstract}

Citrus trees (Citrus spp.) are grown in many areas of the world, and citrus fruits are well known for their beneficial effects on human health (Zou et al., 2016). In 2017, according to the Food and Agriculture Organization of the United Nations (2017), there were more than 130 citrus producing countries, producing more than 124 million tons of fruit per year. Agronomically, citrus is considered a subtropical species and is not tolerant of temperatures below zero or of soils that have poor drainage (Syvertsen and Garcia-Sanchez, 2014). For those specific reasons, citrus trees are usually planted in warm climates with well-drained soils and in areas that are subject to sporadic drought that often require supplemental irrigation.

The accumulation of salt deposits in the soil can be a major problem for growers. Although salts occur naturally in soils in low concentrations, soil salt levels can rise above normal levels and become detrimental to the health of citrus growing in it (Shrivastava and Kumar, 2015). The problem is not only affecting citrus production. It is estimated that more than $6 \%$ of the world's total land

Received for publication 24 Jan. 2019. Accepted for publication 12 Mar. 2019.

This research was supported by the Institute of Food and Agricultural Sciences, University of Florida.

${ }^{1}$ Corresponding author. E-mail: 1.rossi@ufl.edu. and $\approx 20 \%$ of irrigated land are affected by salinity (Munns and Tester, 2008), which is a serious concern in agriculture.

From a plant physiological point of view, salinity is harmful to citrus because the sodium ions are toxic when absorbed and interfere with the plant's normal physiological activities (Tavakkoli et al., 2010). Soil salinization can occur naturally as the result of mineral weathering, a shallow water table, poor drainage, and proximity to coastlines, which can allow seawater to wash into soil during extreme weather events (Chhabra, 2017; Fathi et al., 2017; Shrivastava and Kumar, 2015). Soil can also become salinized from a variety of anthropogenic sources, such as poor irrigation management, irrigating with salinized water, land clearing, and fertilizing with nitrogen and potassium salt (Gorji et al., 2015). Irrigating with poorly managed water also causes secondary salinization of other irrigated lands, which compounds the salinity issue (Mayak et al., 2004). Thus, soil salinity across the world is increasing.

Citrus trees are classified as a salt-sensitive crop (Maas, 1993; Storey and Walker, 1998) because saline irrigation water reduces tree growth and fruit yield more than many other crops (Grieve et al., 2007; Prior et al., 2007). The study of plant root responses to salinity is an active topic area in the plant stress physiology community. Lately, more and more evidence shows that plant roots possess specialized tissues that can prevent and counteract potentially harmful substances (such as $\mathrm{NaCl}$ ) from entering into the vascular system of the plant (Hose et al., 2001; Krishnamurthy et al., 2011; Schreiber et al., 1999). One of the most significant anatomical changes in the root system takes place in the endodermis. This specific anatomical region separates the cortex from the central cylinder and, under environmental stress conditions, can develop specific cell wall modifications called "suberin lamellae." These lamellae originate from the deposition of hydrophobic polymers (i.e., suberin) on the cell walls (Enstone et al., 2002). These are also often associated with other hydrophobic compounds (e.g., waxes) (Schreiber et al., 1999). At an anatomical level, the combination of suberin lamellae with the more investigated Casparian strips (Chen et al., 2011) creates the so-called apoplastic barrier, essentially blocking the apoplastic pathway of water and solute transport in the root and forcing it to go through the cell membranes, which filter it (Steudle, 1994).

Recent publications have reported that apoplastic barriers develop differently when the roots are under stress. Particularly, different apoplastic adjustments in roots modify $\mathrm{Na}^{+}$fluxes to the shoots of olive trees (Olea europaea L.) and Brassica napus L. exposed up to $120 \mathrm{~mm} \mathrm{NaCl}$. (Rossi et al., 2015, 2017a). Similarly, Krishnamurthy et al., (2011) showed that the $\mathrm{Na}^{+}$bypass flow in rice roots was reduced by the deposition of apoplastic barriers. These findings substantiated the role of root apoplastic barriers in plants' tolerance to salt stress.

This study evaluated how citrus 'US-942' rootstock reacted to salinity, which has not been studied before (Bowman and McCollum, 2010). Should 'US-942' rootstock react similarly to the other plant species that have been tested, the apoplastic barriers will develop closer to the root tip with higher soil salinity. Likewise, this study investigated how citrus plants grown on 'US-942' react physiologically to varying levels of salt stress. The chlorophyll (Chl) $a$ and $b$ levels, $g_{\mathrm{S}}$, and biomass are expected to decrease as soil salinity increases Considering the impact of HLB on the citrus industry, it is important to investigate how salt stress can be mitigated and managed.

\section{Materials and Methods}

\section{Establishment}

Sixty 3-month-old 'US-942' citrus rootstock seedlings were purchased from M\&M Citrus Nursery (Fort Pierce, FL). Before purchase, the seedlings were planted in potting medium in nursery plugs mixed in 16-511 fertilizer, as well as treatments of water-soluble 20-20-20 fertilizer and calcium nitrate and potassium nitrate. Thirtysix plants that looked similar and did not have irregularities (forks, disease, excessive or dwarfed height) were selected from the nursery stock to remove outliers. The seedling roots were rinsed clean of nursery soil and repotted in $16.5 \mathrm{~cm}$ wide $\times 18 \mathrm{~cm}$ tall black plastic nursery pots in sand (Sakrete Play Sand, Cincinnati, OH) with a plastic waterproof 
saucer underneath. The pots, plant, and sand without saucer were all adjusted to weigh 3000 $\mathrm{g}$ and the soil surface covered with aluminum foil to prevent algae or weed growth. Plants were acclimated to their new environment for $15 \mathrm{~d}$ before beginning the experiment. During this time, they were watered with $25 \%$ Hoagland solution until the pot without saucer weighed $3450 \mathrm{~g}$. The pots were then numbered and labeled for each experimental group.

\section{Watering and maintenance}

Plants were watered two times per week with 25\% Hoagland solution (Hoagland and Arnon, 1950) containing 0 (control), 30, 60, 90, 120 , or $150 \mathrm{~mm} \mathrm{NaCl}$. Each plant was watered with its Hoagland- $\mathrm{NaCl}$ solution on a scale (Sartorius AG, Göttingen, Germany) and fed $450 \mathrm{~g}$ of solution. Before the next watering, any material that leaked out of the bottom of the pot onto the saucer was poured back into the pot.

\section{Plant height, stem diameter, $g_{s}$}

Plant height, stem diameter, and leaf $g_{\mathrm{S}}$ were measured every $7 \mathrm{~d}$, on day 0 (D0), day 7 (D7), day 14 (D14), day 21 (D21), and day 28 (D28). Height was measured from the soil surface to the top of the highest leaf. Stem diameter was measured using a caliper (Neiko 6" Stainless Steel Digital Caliper, Neiko Tools USA, China) $4 \mathrm{~cm}$ from the soil surface. $g_{\mathrm{S}}$ was measured once each week $1 \mathrm{~d}$ after watering. A steady-state diffusion porometer was used (Decagon Devices model SC-1, Pullman, WA) to measure 1 leaf from the top, middle, and bottom of each plant in the afternoon.

\section{Harvesting}

After $30 \mathrm{~d}$ of treatments, the plants were taken out of their pots in small groups, and all debris was rinsed off with deionized water. Each plant was then cut just above the roots and the aboveground parts and roots were weighed separately on an analytical scale (Sartorius AG, Göttingen, Germany). Samples of roots were placed in methanol, and leaf lamina were placed in $N, N$-dimethyl formamide (DMF). Once the samples were taken, the roots and aboveground plant parts were placed in separately labeled brown paper bags.

\section{Chlorophyll a and $b$}

Immediately after harvest, $100 \mathrm{mg}$ of leaf lamina were cut from each plant, keeping the pieces relatively the same size and avoiding major leaf veins. The cut lamina was then placed in $25 \mathrm{~mL}$ of DMF and kept at $4{ }^{\circ} \mathrm{C}$ in the dark. After $48 \mathrm{~h}$, the samples were tested in an ultraviolet-visible spectrophotometer (Thermo Scientific Genesys 50, Hampton, $\mathrm{NH})$ in quartz cuvettes at 664 and $647 \mathrm{~nm}$. The resulting readings were then put into the following formulae (Moran, 1982):

$$
\begin{aligned}
\text { Chl } a & =12.64 \cdot \mathrm{A} 664-2.99 \cdot \mathrm{A} 647 \\
\mathrm{Chl} b & =-5.6 \cdot \mathrm{A} 664+23.26 \cdot \mathrm{A} 647
\end{aligned}
$$

\section{Plant biomass}

After harvest, measuring fresh weight, and taking samples for $\mathrm{Chl} a$ and $b$ measurements and apoplastic barrier measurements, the aboveground plant parts and roots were placed in separate brown paper bags and put in a $70{ }^{\circ} \mathrm{C}$ drying oven for $6 \mathrm{~d}$. Plant bags were not clumped too closely together to ensure proper air circulation and even drying.

\section{Apoplastic barriers}

Staining. After harvest, 4 or 5 fresh, healthy-looking root samples of $\approx 5$ to $6 \mathrm{~cm}$ were taken from each plant (being sure to include the root tip) and placed in $15-\mathrm{mL}$ tubes with enough methanol to completely cover the roots. They were stored at $4{ }^{\circ} \mathrm{C}$ until needed for staining. For staining, one root from each treatment was cut to $4 \mathrm{~cm}$ (from root tip) and soaked in three water baths of $5 \mathrm{~min}$ each to remove the methanol. They were then placed in 2-mL micro centrifuge tubes with $0.1 \%$ fluorol yellow $088(\mathrm{w} / \mathrm{v})$ in lactic acid (modified from Lux et al., 2005). The tubes were placed in a water bath (Fisher Scientific, Isotemp GPD10 Hampton, NH) at $70{ }^{\circ} \mathrm{C}$ in the dark for $30 \mathrm{~min}$. Afterward, they were washed in another three water baths of 5 min each in the dark. The samples were then placed in 2-mL micro centrifuge tubes with $0.5 \%$ aniline blue $(\mathrm{w} / \mathrm{v})$ in distilled water in the dark for 30 min (modified from Lux et al., 2005). After this staining, the samples were placed in three water baths of 10 min each in the dark. Samples were then taken out of the water baths and placed in 2 $\mathrm{mL}$ micro centrifuge tubes with $50 \%$ glycerol $(\mathrm{w} / \mathrm{w})$, for microscopic analysis.

Microscopy. Microscopy was done with a Leica fluorescence microscope (Leica DM 1000 LED, Wetzlar, Germany) connected to an RGB camera (Leica DMC2900, Wetzlar, Germany). Soon after staining, one sample was taken out of the glycerol and placed on the cutting surface with a small amount of glycerol on it to prevent drying. For each 0.5 $\mathrm{cm}$, free-hand sections were cut and mounted together on a slide in a drop of glycerol, making sure each cross section was flat side up. The slide was then placed on the microscope stage, and each cross section was viewed to see the average percentage of apoplastic barrier that developed, and this was recorded for that $0.5 \mathrm{~cm}$. This was repeated for each $0.5 \mathrm{~cm}$ of each root. Care was taken not to leave the samples under the microscope for too long, so the stain did not lose its fluorescence. All microscopical investigations were conducted at the University of Florida, Institute of Food and Agricultural Sciences, Indian River Research and Education Center, Fort Pierce, FL.

\section{Experimental design and statistical analysis}

The experiment was set up using a completely randomized experimental design $(n=6)$. Once collected, data were subjected to one-way analysis of variance. Means separation between treatments was obtained using Tukey's test $(P \leq 0.05)$. Minitab 17 Statistical Software (Minitab Inc., State College, PA) was used for the data analyses and interpretation.

\section{Results}

\section{Plant growth and development}

Significant differences in plant heights (cm) were recorded after D7. Particularly plants treated with $30 \mathrm{~mm} \mathrm{NaCl}$ showed a height increase of $17.3 \%$ compared with the control. Plants treated with higher levels of $\mathrm{NaCl}$ showed an average height decrease of more than $10.1 \%$ compared with control. (Fig. 1A). A similar trend was noted at D21 and D28. Interestingly, at the end of the experiment (D28), plants treated with $30 \mathrm{~mm} \mathrm{NaCl}$ were $5.4 \%$ taller than the control ones, while plants treated with 90,120 , and $150 \mathrm{~mm}$ were $20.2 \%$ (on average) shorter than the control plants. Plants treated with $60 \mathrm{~mm}$ $\mathrm{NaCl}$ showed results that were similar to the control plants (Fig. 1B).

Similarly, significant changes in the diameter were noted after D7 (Fig. 1B) Plants treated with $30 \mathrm{~mm} \mathrm{NaCl}$ showed a $10.6 \%$ increase in diameter (millimeters), whereas plants treated with higher $\mathrm{NaCl}$ concentrations showed significant decrease (5.2\%) compared with the control. Significant changes were also reported after D21 and D28. Particularly, at the end of the experiment (D28), compared with the control group, plants treated with $30 \mathrm{~mm} \mathrm{NaCl}$ increased in diameter by $8.1 \%$, whereas plants treated with 150 and $120 \mathrm{~mm}$ $\mathrm{NaCl}$ decreased in diameter by $8.5 \%$ and $9.1 \%$, respectively. Plants treated with 60 and $90 \mathrm{~mm} \mathrm{NaCl}$ did not show any significant changes compared with control (Fig. 1B).

\section{Plant biomass}

After $28 \mathrm{~d}$ of treatment plants treated with $30 \mathrm{~mm} \mathrm{NaCl}$ showed a significant increase in fresh weight $(\mathrm{FW})$ in both root $(8.1 \%)$ and leaf $(8.9 \%)$ tissues, compared with control plants. A decrease was noticed in plants treated with $60,90,120$, or $150 \mathrm{~mm} \mathrm{NaCl}$. Particularly, plants treated with the highest concentrations (i.e., 120 and $150 \mathrm{~mm} \mathrm{NaCl}$ ) showed a $16.6 \%$ decrease in root $\mathrm{FW}$ and $17.2 \%$ decrease in leaf FW (Fig. 2A).

A similar trend was observed for root and leaf dry weights (DW). When plants were treated with $30 \mathrm{~mm} \mathrm{NaCl}$, root DW increased by $4.8 \%$, and leaf DW increased by $14.4 \%$ compared with the control plants. A decrease was noticed for plants treated with 60, 90, 120 , and $150 \mathrm{~mm} \mathrm{NaCl}$. Particularly, plants treated with $150 \mathrm{~mm} \mathrm{NaCl}$ showed a decrease of $7.1 \%$ in root DW and of $9.2 \%$ in leaf DW, compared with the control (Fig. 2B).

\section{$g_{\mathrm{S}}$ and chlorophyll contents}

$g_{\mathrm{S}}$ measurements were taken every $7 \mathrm{~d}$, at the same time of the height and stem diameter measurements (Fig. 3). Significant changes were noted starting after D7, and the changes consistently progressed until the end of the experiment (D28). No significant changes were reported on D21, mostly due to inclement weather. Interestingly, at the end of the experiment, a clear trend was observed. Control plants outperformed all the treated plants. When compared with the controls, plants treated with $30,60,90,120$, and $150 \mathrm{~mm} \mathrm{NaCl}$ 

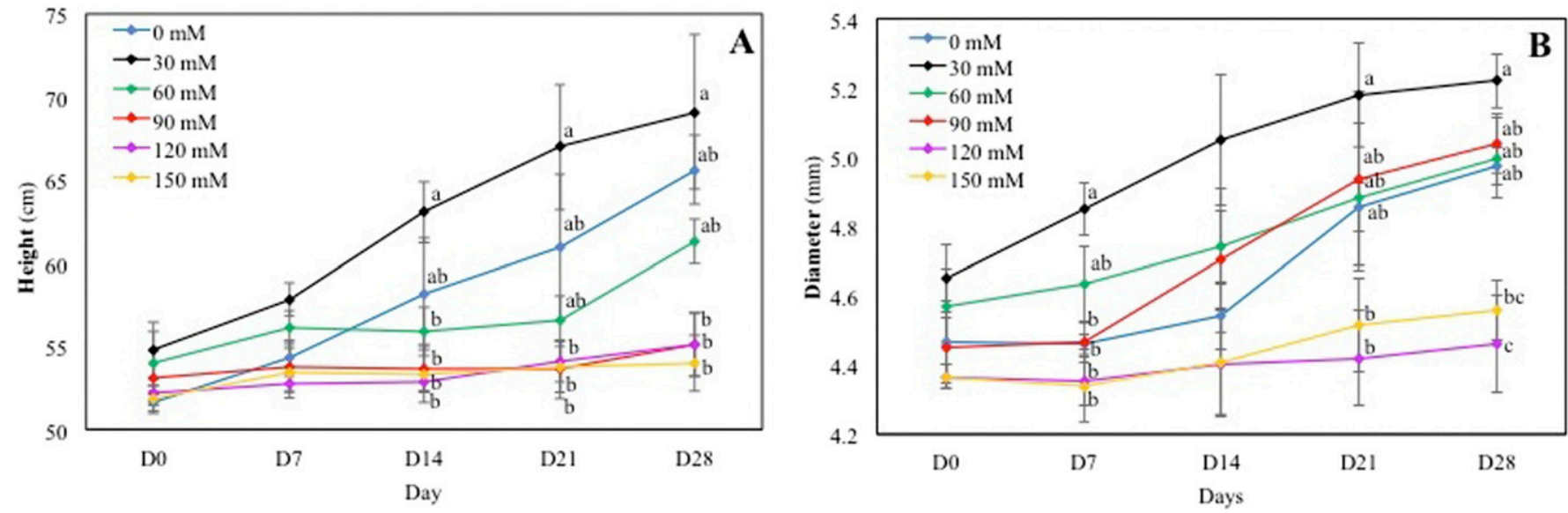

Fig. 1. Height (A) and diameter (B) of Citrus 'US-942' seedlings grown in the presence of 0 (control), 30, 60, 90, 120, and $150 \mathrm{~mm} \mathrm{NaCl}$. Means labeled with different letters are significantly different by Tukey's post hoc test $(P<0.05)$. Error bars represent the SD $(\mathrm{n}=6)$.
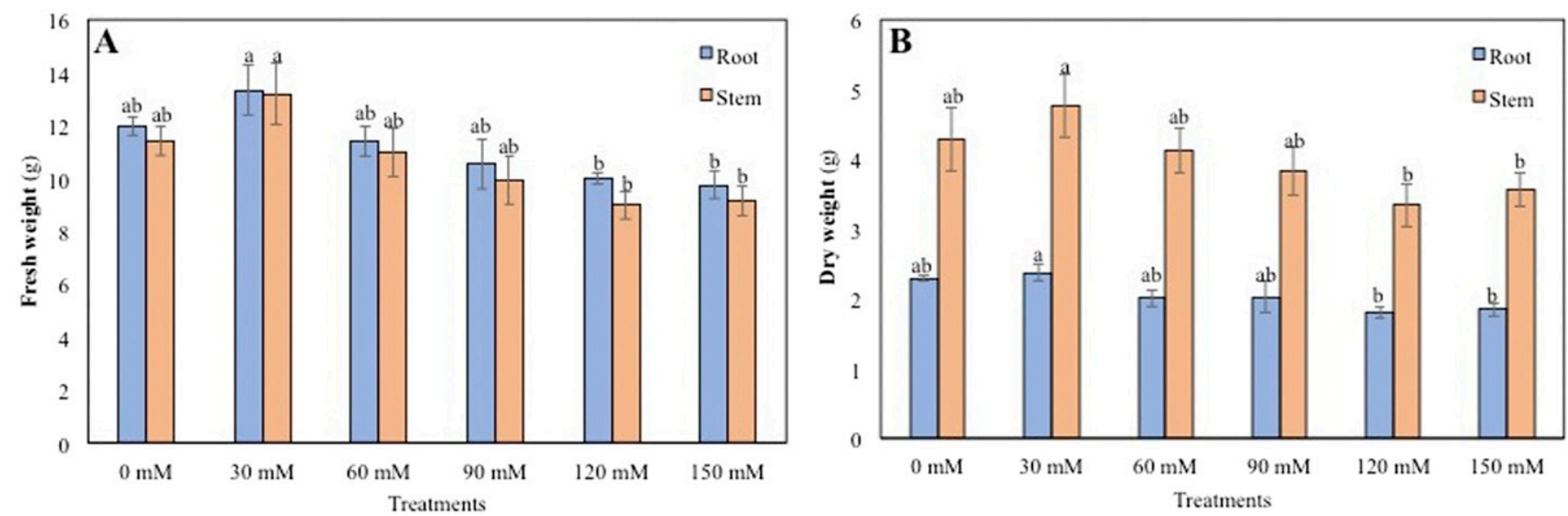

Fig. 2. Fresh weight (A) and dry weight (B) of Citrus 'US-942' seedlings grown in the presence of 0 (control), 30, 60, 90,120 , and $150 \mathrm{~mm}$ NaCl for $28 \mathrm{~d}$. Means labeled with different letters are significantly different by Tukey's post hoc test $(P<0.05)$. Error bars represent the SD $(\mathrm{n}=6)$.

had decreased $g_{\mathrm{S}}$ by $29.2 \%, 36.6 \%, 52.1 \%$, $54.4 \%$, and $63.2 \%$ respectively.

Chlorophyll contents were measured at the end of the experiment (D27). Control plants showed the highest levels of both Chl $a$ and $b$. All the treated plants showed a significant decrease that was directly related to the treatment level (i.e., $\mathrm{NaCl}$ concentration). Compared with the control, plants treated with $30 \mathrm{~mm} \mathrm{NaCl}$ showed a $25.4 \%$ decrease in Chl $a$ and a $38.1 \%$ decrease in Chl $b$. The levels of Chls maintain a decreasing trend throughout all the treatments showing a $70.2 \%$ decrease in Chl $a$ and an $80.3 \%$ decrease in $\mathrm{Chl} b$ in plant treated with $150 \mathrm{~mm} \mathrm{NaCl}$, compared with controls.

\section{Root apoplastic barrier development}

New roots, developed during the trial, were collected from each treated plant at the end of the experiment (D27). Fluorescence microscopic analyses were performed up to $4 \mathrm{~cm}$ from the root tip. Bright-field micrographs showing sections of roots are shown in Fig. 4A and B, whereas fluorescence micrographs reporting the different development of the apoplastic barriers (i.e., not yet formed, and almost completely formed) are reported in Fig. 4C and D.

A schematic representation of the barrier development is reported in Fig. 4E. Overall, when plants are treated with $\mathrm{NaCl}$, root barriers developed closer to the root tip, particularly at $30,90,120$, and $150 \mathrm{~mm}$. The root barrier development closer to the root tip is directly related to the $\mathrm{NaCl}$ concentration applied in almost all the treatments. For convenience, measurements of the apoplastic barriers were measured in increments of the barrier's development (less than 50\% developed and more than $50 \%$ developed). Significant differences and detailed results are reported in Table 1.

\section{Discussion}

Salinity represents one of the most severe environmental factors limiting crop productivity worldwide. Numerous cultivated species are sensitive to soil salinity, and the area of land affected by salt stress is increasing day by day (Shrivastava and Kumar, 2015). Citrus is a major horticultural crop and is relatively salt sensitive (Storey and Walker, 1998). This study investigated the impact of different $\mathrm{NaCl}$ concentrations $(0,30,60,90$, 120 , or $150 \mathrm{~mm}$ ) on the plant physiology and root anatomy of citrus rootstock 'US-942' in an innovative way. In fact, the 'US-942' rootstock has been available since 2010 , but its soil salinity preferences have not been listed in the release note (Bowman and McCollum, 2010), nor have its physiological and root anatomical adjustments under salt stress been tested in any other study. Here, we combined traditional tree physiological measurements with new root anatomical microscopy techniques (i.e., the study of root apoplastic barriers), which we applied to citrus for the first time.

Consistent with previous results obtained on citrus (Storey and Walker, 1998; Syvertsen et al., 1989; Syvertsen and Garcia-Sanchez, 2014), our study showed that high $\mathrm{NaCl}$ concentrations inhibited citrus height, stem diameter, and biomass (FW and DW) compared with control. $\mathrm{NaCl}$ concentrations of 120 and $150 \mathrm{~mm}$ were particularly detrimental for plant growth and development. This saltspecific effect on plant growth combined 

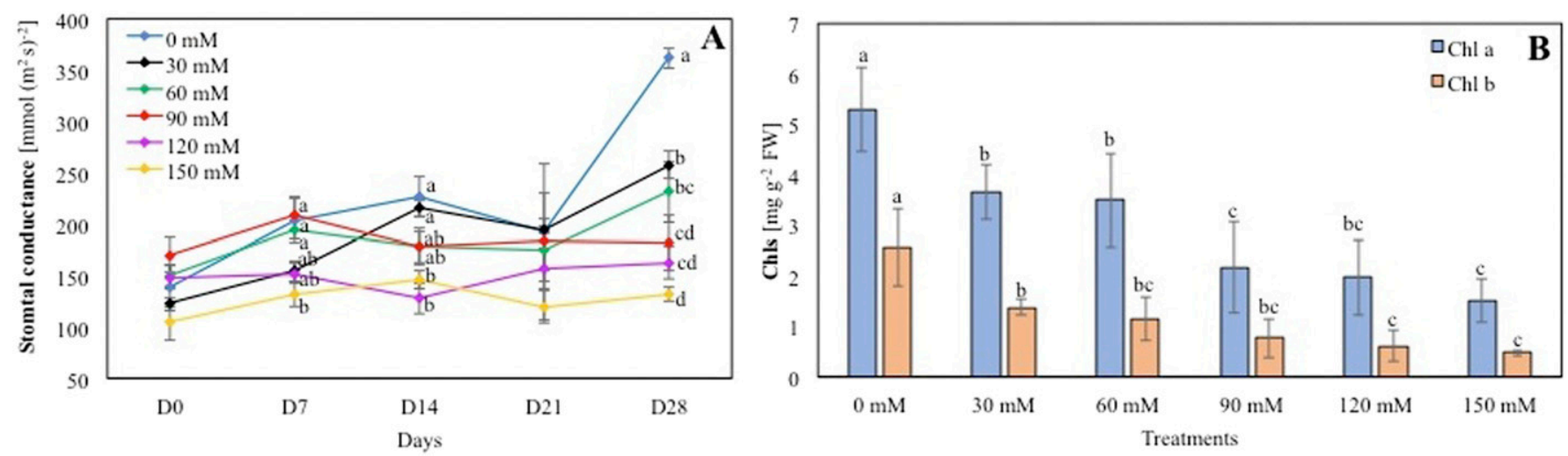

Fig. 3. $g_{\mathrm{S}}(\mathbf{A})$ and chlorophyll $a$ and $b$ contents (B) of Citrus 'US-942' seedlings grown in the presence of 0 (control), 30, 60, 90, 120, and 150 mu NaCl. Means labeled by different letters are significantly different by Tukey's post hoc test $(P<0.05)$. Error bars represent the SD $(n=6)$.
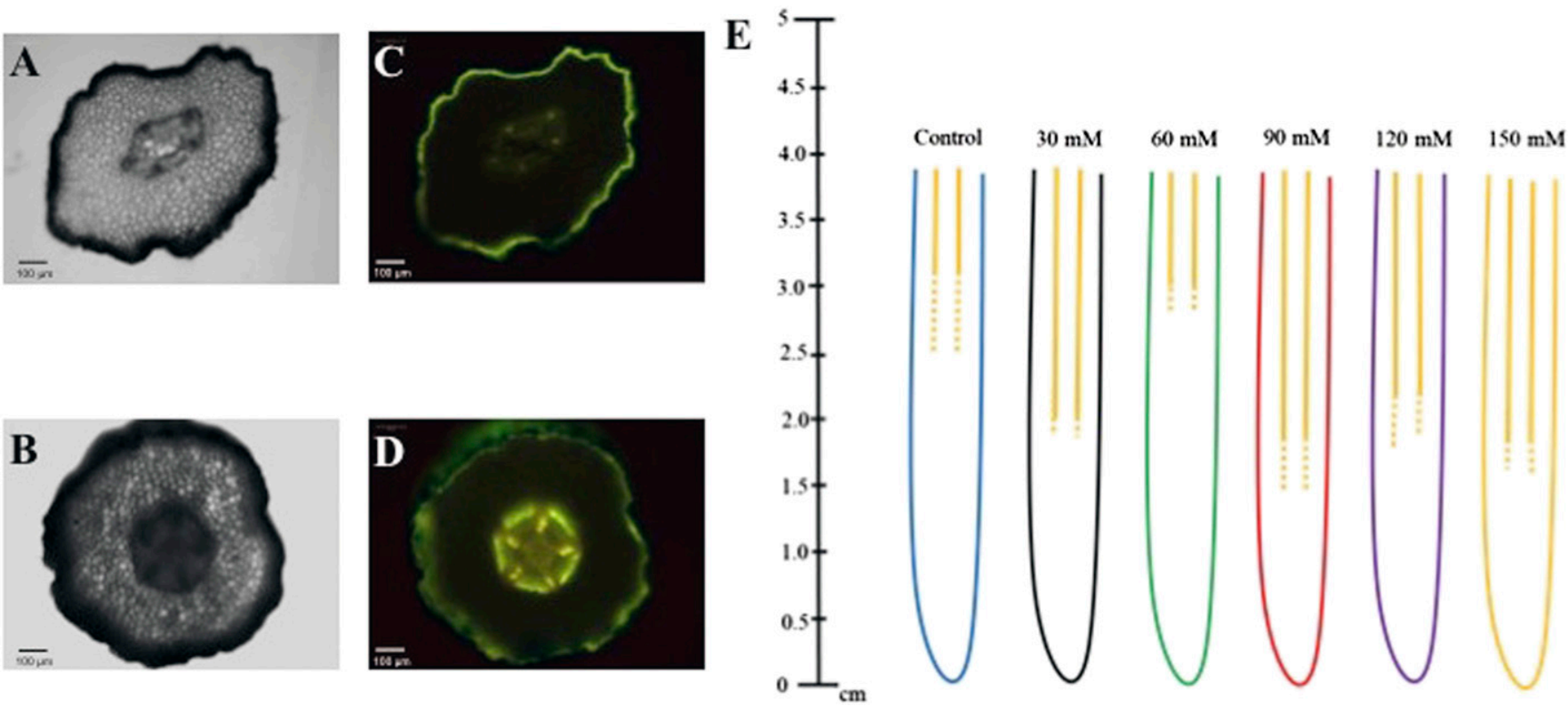

Fig. 4. Root anatomical analyses of 'US-942' citrus seedlings exposed to 0, 30, 60, 90, 120, and $150 \mathrm{~mm} \mathrm{NaCl}$. (A and B) Examples of bright field microscopy image taken at 1.50 and $3.00 \mathrm{~cm}$ from the root apex (control). (C and D) Examples of fluorescence microscopy. The images are the same as the bright field (A and $\mathbf{B}$ ), but here endodermal suberin lamellae (yellow) can be visualized under a fluorescent light. (E) Schematic representation of endodermal suberin lamellae development. Dot lines represent less then 50\% development, and full lines represent barriers that are more $50 \%$ developed $(\mathrm{n}=3$ ).

Table 1. Distances from the root apex of 'US-942' citrus seedlings exposed to $0,30,60,90,120$, and $150 \mathrm{~mm} \mathrm{NaCl}$. Measurements took place at the end of the experiment (D28). Reported values are means $(\mathrm{n}=3) \pm$ SD. Different letters indicate significant differences by Tukey's post hoc test $(P \leq 0.05)$.

\begin{tabular}{|c|c|c|c|c|c|c|}
\hline Root barriers $(\mathrm{cm})$ & Control & $30 \mathrm{~mm}$ & $60 \mathrm{~mm}$ & $90 \mathrm{~mm}$ & $120 \mathrm{~mm}$ & $150 \mathrm{~mm}$ \\
\hline More than $50 \%$ developed & $3.17 \pm 0.29 \mathrm{a}$ & $2.01 \pm 0.49 \mathrm{c}$ & $3.01 \pm 0.87 \mathrm{ab}$ & $1.83 \pm 0.29 \mathrm{c}$ & $2.33 \pm 0.29 b c$ & $1.84 \pm 0.29 \mathrm{c}$ \\
\hline
\end{tabular}

hormonal responses and osmotic stress adjustments. At the beginning, the reduction in plant biomass is due to hormonal signals generated by the roots (Munns and Tester, 2008). Subsequently, when excessive amounts of salt enter the plant, reaching toxic levels in the older transpiring leaves, oxidative stress compromises the photosynthetic machinery to a level that cannot sustain growth (Munns, 2002). Also, the decreased root growth can be a consequence of a salt-induced $\mathrm{Ca}^{2+}$ deficiency. In fact, $\mathrm{NaCl}$ concentration in the nutrient solution lowers the activity of $\mathrm{Ca}^{2+}$ (Cramer et al., 1988), and root growth can be severely and quickly affected (Munns, 2002). Results obtained from our experiment are in accordance with other studies conducted on citrus (Storey and Walker, 1998; Syvertsen and Garcia-Sanchez, 2014). Accordingly, at higher levels of $\mathrm{NaCl}$ a salt-specific decrease in all the physiological parameters occurred. Interestingly, plants treated with $30 \mathrm{~mm} \mathrm{NaCl}$ did not show these specific symptoms. They, conversely, outgrew the control in terms of height, diameter, and root and leaf biomass (FW and DW). This specific phenomenon can be classified as a specific mild-stress response.

In recent decades, mild to moderate stresses (e.g., drought, temperature, salinity) have been used for managing plant growth and fruit quality in several species (Chaves et al., 2009; Clauw et al., 2015; Kursar et al., 2009; Rossi et al., 2016; Shrivastava and Kumar, 2015). Several studies indicated the existence of a robust response over mild salt stress, compared with the severe ones. Koyro et al. (1993) concluded that mild salt stress leads to a higher biomass and root length in Sorghum sp. but not Spartina sp. More 
recently, Zolla et al. (2010) reported that mild salt stress promotes auxin accumulation, which translated to a more pronounced development of root primordia. This prevents root developmental arrest at the preemergence stage. Similarly, Pavlović et al. (2018) reported that salinity affects auxin distribution in Chinese cabbage [Brassica rapa L. ssp. pekinensis (Lour.) Hanelt] root, promoting changes in root system architecture and lateral root formation. Particularly, upon salinity treatments, Indole-3-acetic acid (IAA) level was elevated in a dosedependent manner. Our results showed a similar trend. Increases in biomass (root and leaves), height, and diameter were recorded when the plants were treated with $30 \mathrm{~mm}$ $\mathrm{NaCl}$. This can be a specific response to a mild salt stress, indicating that 'US-942' react to mild salinity stress activating intracellular signaling pathways, linking salinity to root development. Therefore, the aboveground biomass also sought an increase, due to a more developed root system able to uptake more water and nutrients. Conversely, when the stress was moderate and extreme $(60,90$, 120 , and $150 \mathrm{~mm} \mathrm{NaCl}$ ), the overall biomass was hindered, and the plants' growth and development was inhibited, due to the aforementioned $\mathrm{NaCl}$ toxicity effects.

All the treated citrus plants responded to salinity by altering their physiological parameters to maintain their water balance. A salt-specific response was annotated in all the treated plants for both $g_{\mathrm{S}}$ and chlorophyll contents. Because physiological responses to salinity stress are highly complex and involve the interplay of limitations taking place at different sites of the plant, a root anatomical study was also performed. The root system is, in fact, the first part of the plant that is in direct contact with the soil and is the first organ to cope with different environmental constraints (e.g., salinity, drought). Root performance in the presence of pollutants and toxic ions relies on the Casparian strip and suberin lamellae formed in the root rhizodermis and exodermis (Chen et al., 2011; Kim et al., 2018; Kreszies et al., 2019). Plants react to environmental constraints by developing apoplastic barriers close to the root apex to mitigate the intrusion of toxic ions.

Our results indicated that 'US-942' roots can develop endodermal apoplastic barriers in response to salt stress. This finding confirmed, for the first time, that $\mathrm{NaCl}$ interferes with root barrier formation in citrus. It has, in fact, been reported that different apoplastic adjustments in roots play a role in modifying sodium intrusion in other species, but no information was available for citrus. Several studies demonstrated differences in $\mathrm{Na}^{+}$rootshoot fluxes of olive trees (Olea europea L.), soybean [Glycine $\max$ (L.) Merr], and canola (Brassica napus L.) when exposed up to $120 \mathrm{~mm} \mathrm{NaCl}$ (Rossi et al., 2015, 2017a, 2017b). Moreover, Krishnamurthy et al. (2011) reported that the $\mathrm{Na}^{+}$bypass-flow in rice (Oryza sativa L.) roots was reduced by the deposition of apoplastic barriers. These findings substantiated the role of root apoplastic barriers in plants' tolerance to salt stress. Interestingly, the level of barrier development strongly correlated with the different sodium chloride concentration treatments (as shown in Fig. 4). Particularly, a closer development of the root barriers to the root apex was reported when plants were subjected to mild stress $(30 \mathrm{~mm} \mathrm{NaCl})$ and severe stress (120 and $150 \mathrm{~mm} \mathrm{NaCl})$. The development of suberized barriers closer to the root tip in the $30 \mathrm{~mm} \mathrm{NaCl}$ treated plants can be a result of a mild stress response leading to an early development of apoplastic barriers, while in the other treatments, the development correlates with the salt concentrations.

From the results, it seems reasonable to conclude that one important physiological and anatomical response of 'US-942' is the early development of root barriers when exposed to mild $\mathrm{NaCl}$ stress (Fig. 4). Results indicated that 'US-942' can tolerate mild $\mathrm{NaCl}$ stress but not moderate or severe stresses. Formation of apoplastic barriers and increase in the root biomass could be two possible mechanisms that give 'US-942' mild $\mathrm{NaCl}$ stress tolerance. For maximum productivity, 'US-942' can perform in fields that have mild to low salt content. Planting the right rootstock as well as practicing farming methods that reduce salinity buildup overtime will help in maintaining production while ensuring healthy and nonsalinized soils. More investigations on the mechanisms at cellular levels and on the uptake of nutrients by different varieties and rootstocks will further enhance the understanding of the potential salt tolerance traits in citrus.

\section{Literature Cited}

Bowman, K. and G. McCollum. 2010. Notice to fruit growers and nurserymen relative to the naming and release of the US-942 citrus rootstock. U.S. Department of Agriculture, Agricultural Research Service, Washington, DC.

Chaves, M.M., J. Flexas, and C. Pinheiro. 2009 Photosynthesis under drought and salt stress: Regulation mechanisms from whole plant to cell. Ann. Bot. (Lond.) 103:551-560.

Chen, T., X. Cai, X. Wu, I. Karahara, L. Schreiber, and J. Lin. 2011. Casparian strip development and its potential function in salt tolerance. Plant Signal. Behav. 6:1499-1502.

Chhabra, R. 2017. Soil salinity and water quality. Routledge, London.

Clauw, P., F. Coppens, K. De Beuf, S. Dhondt, T. Van Daele, K. Maleux, V. Storme, L. Clement, N. Gonzalez, and D. Inze. 2015. Leaf responses to mild drought stress in natural variants of Arabidopsis thaliana. Plant Physiol. 167:800-816.

Cramer, G.R., E. Epstein, and A. Läuchli. 1988. Kinetics of root elongation of maize in response to short-term exposure to $\mathrm{NaCl}$ and elevated calcium concentration. J. Expt. Bot. 39:1513-1522.

Enstone, D.E., C.A. Peterson, and F. Ma. 2002. Root endodermis and exodermis: structure, function, and responses to the environment. J. Plant Growth Regul. 21:335-351.

Food and Agriculture Organization of the United Nations. 2017. Citrus fruit, fresh and processed, Statistical Bulletin, Rome.

Fathi, A., M. Zahedi, and S. Torabian. 2017. Effect of interaction between salinity and nanoparticles
$\left(\mathrm{Fe}_{2} \mathrm{O}_{3}\right.$ and $\left.\mathrm{ZnO}\right)$ on physiological parameters of Zea mays L. J. Plant Nutr. 40:2745-2755.

Gorji, T., A. Tanik, and E. Sertel. 2015. Soil Salinity Prediction, Monitoring and Mapping Using Modern Technologies. Procedia Earth and Planetary Science 15:507-512.

Grieve, A., L. Prior, and K. Bevington. 2007. Longterm effects of saline irrigation water on growth, yield, and fruit quality of 'Valencia' orange trees. Austral. J. Agr. Res. 58:342-348.

Hoagland, D.R. and D.I. Arnon. 1950. The waterculture method for growing plants without soil. Circular 347. California agricultural experiment station.

Hose, E., D. Clarkson, E. Steudle, L. Schreiber, and W. Hartung. 2001. The exodermis: A variable apoplastic barrier. J. Expt. Bot. 52:2245-2264.

Kim, Y.X., K. Ranathunge, S. Lee, Y. Lee, D. Lee, and J. Sung. 2018. Composite transport model and water and solute transport across plant roots: An update. Front. Plant Sci. 9:193.

Koyro, H.-W., R. Stelzer, and B. Huchzermeyer. 1993. ATPase activities and membrane fine structure of rhizodermal cells from sorghum and spartina roots grown under mild salt stress. Bot. Acta 106:110-119.

Kreszies, T., N. Shellakkutti, A. Osthoff, P. Yu, J.A. Baldauf, V.V. Zeisler-Diehl, K. Ranathunge, F. Hochholdinger, and L. Schreiber. 2019. Osmotic stress enhances suberization of apoplastic barriers in barley seminal roots: Analysis of chemical, transcriptomic and physiological responses. New Phytol 221:180-194.

Krishnamurthy, P., K. Ranathunge, S. Nayak, L. Schreiber, and M. Mathew. 2011. Root apoplastic barriers block $\mathrm{Na}+$ transport to shoots in rice (Oryza sativa L.). J. Expt. Bot. 62:4215-4228.

Kursar, T.A., B.M.J. Engelbrecht, A. Burke, M.T. Tyree, B.E. Omari, and J.P. Giraldo. 2009. Tolerance to low leaf water status of tropical tree seedlings is related to drought performance and distribution. Funct. Ecol. 23:93-102.

Lux, A., S. Morita, J. Abe, and K. Ito. 2005. An improved method for clearing and staining free-hand sections and whole-mount samples. Ann. Bot. (Lond.) 96:989-996.

Maas, E. 1993. Salinity and citriculture. Tree Physiol. 12:195-216.

Mayak, S., T. Tirosh, and B.R. Glick. 2004. Plant growth-promoting bacteria confer resistance in tomato plants to salt stress. Plant Physiol. Biochem. 42:565-572.

Moran, R. 1982. Formulae for determination of chlorophyllous pigments extracted with $N, N$ dimethylformamide. Plant Physiol. 69:13761381 .

Munns, R. 2002. Comparative physiology of salt and water stress. Plant Cell Environ. 25:239-250.

Munns, R. and M. Tester. 2008. Mechanisms of salinity tolerance. Annu. Rev. Plant Biol. 59:651-681.

Pavlović, I., A. Pěnčík, O. Novák, V. Vujčić, S. Radić Brkanac, H. Lepeduš, M. Strnad, and B. Salopek-Sondi. 2018. Short-term salt stress in Brassica rapa seedlings causes alterations in auxin metabolism. Plant Physiol. Biochem. 125:74-84.

Prior, L., A. Grieve, K. Bevington, and P. Slavich. 2007. Long-term effects of saline irrigation water on 'Valencia' orange trees: Relationships between growth and yield, and salt levels in soil and leaves. Austral. J. Agr. Res. 58:349-358.

Rossi, L., M. Borghi, A. Francini, X. Lin, D.-Y. Xie, and L. Sebastiani. 2016. Salt stress induces differential regulation of the phenylpropanoid pathway in Olea europaea cultivars Frantoio (salt-tolerant) and Leccino (salt-sensitive). J. Plant Physiol. 204:8-15. 
Rossi, L., A. Francini, A. Minnocci, and L. Sebastiani. 2015. Salt stress modifies apoplastic barriers in olive (Olea europaea L.): A comparison between a salt-tolerant and a salt-sensitive cultivar. Scientia Hort. 192:38-46.

Rossi, L., W. Zhang, and X. Ma. 2017a. Cerium oxide nanoparticles alter the salt stress tolerance of Brassica napus L. by modifying the formation of root apoplastic barriers. Environ. Pollut. 229:132-138.

Rossi, L., W. Zhang, A.P. Schwab, and X. Ma. 2017 b. Uptake, accumulation, and in planta distribution of coexisting cerium oxide nanoparticles and cadmium in Glycine max (L.) Merr. Environ. Sci. Technol. 51:12815-12824.
Schreiber, L., K. Hartmann, M. Skrabs, and J. Zeier. 1999. Apoplastic barriers in roots: Chemical composition of endodermal and hypodermal cell walls. J. Expt. Bot. 50:1267-1280.

Shrivastava, P. and R. Kumar. 2015. Soil salinity: A serious environmental issue and plant growth promoting bacteria as one of the tools for its alleviation. Saudi J. Biol. Sci. 22:123-131.

Steudle, E. 1994. Water transport across roots. Plant Soil 167:79-90.

Storey, R. and R. Walker. 1998. Citrus and salinity. Scientia Hort. 78:39-81.

Syvertsen, J., B. Boman, and D. Tucker. 1989. Salinity in Florida citrus production. Proc. Fla. State Hort. Soc. 102:61-64.
Syvertsen, J.P. and F. Garcia-Sanchez. 2014. Multiple abiotic stresses occurring with salinity stress in citrus. Environ. Exp. Bot. 103:128-137.

Tavakkoli, E., P. Rengasamy, and G.K. McDonald. 2010. High concentrations of $\mathrm{Na}+$ and $\mathrm{Cl}-$ ions in soil solution have simultaneous detrimental effects on growth of fava bean under salinity stress. J. Expt. Bot. 61:4449-4459.

Zolla, G., Y.M. Heimer, and S. Barak. 2010. Mild salinity stimulates a stress-induced morphogenic response in Arabidopsis thaliana roots. J. Expt. Bot. 61:211-224.

Zou, Z., W. Xi, Y. Hu, C. Nie, and Z. Zhou. 2016. Antioxidant activity of citrus fruits. Food Chem. 196:885-896. 